\title{
AVALIAÇÃO DO SISTEMA DE LIMPEZA CICLONE MAIS LAVADOR VENTURI NA COLETA DE MATERIAL PARTICULADO UTILIZANDO O SOFTWARE ASPEN PLUS
}

\author{
A. E. DE OLIVEIRA ${ }^{1}$, V. G. G. BÉTTEGA ${ }^{1}$ \\ ${ }^{1}$ Universidade Federal de São Carlos, Departamento de Engenharia Química \\ E-mail para contato: alessandroestarque@gmail.com
}

\begin{abstract}
RESUMO - Com o objetivo de propor um sistema de limpeza economicamente mais viável, eficiente e com menor quantidade de resíduos, o presente trabalho utilizou o simulador Aspen Plus ${ }_{\circledR}$ para avaliar um sistema composto por ciclone em série a um lavador Venturi para a coleta de particulado gerado na queima de bagaço de cana-de-açúcar, avaliando-se o consumo de água e a queda de pressão em comparação com um lavador Venturi atuando isoladamente. Verificou-se que o ciclone capturou partículas maiores, reduzindo o consumo de água no lavador e a queda de pressão global $(44,44 \%$ e $60 \%$, respectivamente, do consumido pelo sistema composto por um único lavador Venturi), enquanto o lavador coletou partículas mais finas que os ciclones não capturaram de forma eficiente.
\end{abstract}

\section{INTRODUÇÃO}

O bagaço é o principal resíduo do processamento da cana-de-açúcar para a obtenção de açúcar e etanol. Tem sido historicamente utilizado como combustível dentro das usinas, sendo que apenas metade do bagaço produzido dentro de uma usina já é suficiente para satisfazer suas necessidades energéticas (ICIDCA, 1999). A Figura 1 exibe a distribuição acumulada do particulado gerado na queima do bagaço em uma unidade de cogeração de energia e a distribuição do particulado após a lavagem do gás sujo em um lavador do tipo Venturi presente nesta unidade. Cada medição foi realizada em duplicata (Medição 1 e Medição 2).

Figura 1 - Granulometria do particulado de cana antes (a) e após (b) a lavagem do gás.
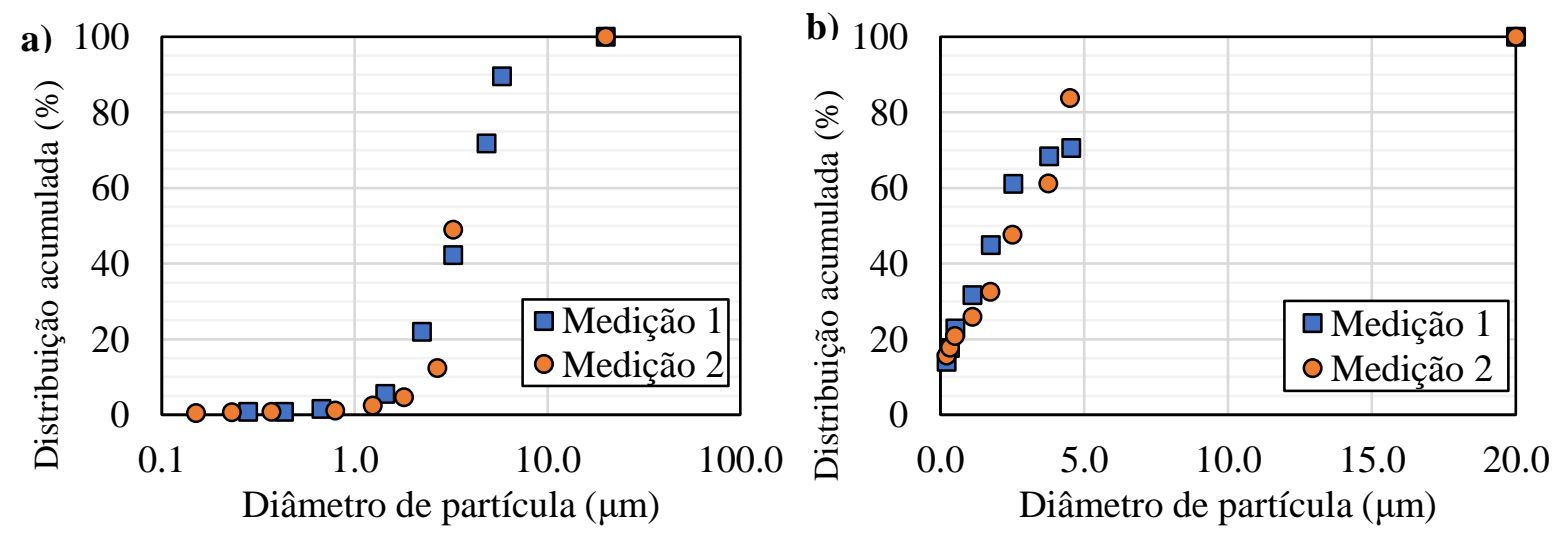

Fonte: TEIXEIRA (2005) 
Na Figura 1, verifica-se que o particulado emitido na queima do bagaço possuía majoritariamente diâmetros menores que $10 \mu \mathrm{m}$, sendo esta uma faixa granulométrica potencialmente danosa à saúde humana e denominada $\mathrm{PM}_{10}$ (WHO, 2006).

Para o controle industrial de particulados, são utilizados equipamentos cujos princípios de funcionamento e restrições mecânicas os tornam úteis para aplicações específicas. Por exemplo, lavadores Venturi possuem elevada eficiência em uma ampla faixa de granulometria, são capazes de reter gases tóxicos ou corrosivos a partir da lavagem com líquido atomizado e podem ser utilizados no tratamento de correntes quentes. Por outro lado, demandam alto conteúdo energético e posterior tratamento do líquido de lavagem, encarecendo o processo. Ciclones, por sua vez, demandam baixos gastos energéticos e não necessitam de líquido de limpeza, embora possuam reduzida eficiência para partículas abaixo de $10 \mu \mathrm{m}$ (SUTHERLAND, 2008).

Portanto, este trabalho objetivou avaliar um sistema de limpeza composto por um ciclone em série a um lavador Venturi para o tratamento do gás proveniente da queima de bagaço de cana-de-açúcar utilizando o simulador Aspen Plus® e estabelecendo comparações com um sistema composto unicamente por um lavador Venturi.

\section{METODOLOGIA}

A Figura 2 exibe o fluxograma dos sistemas de limpeza implementados no simulador.

Figura 2 - Sistemas de lavagem de gás implementados no software.

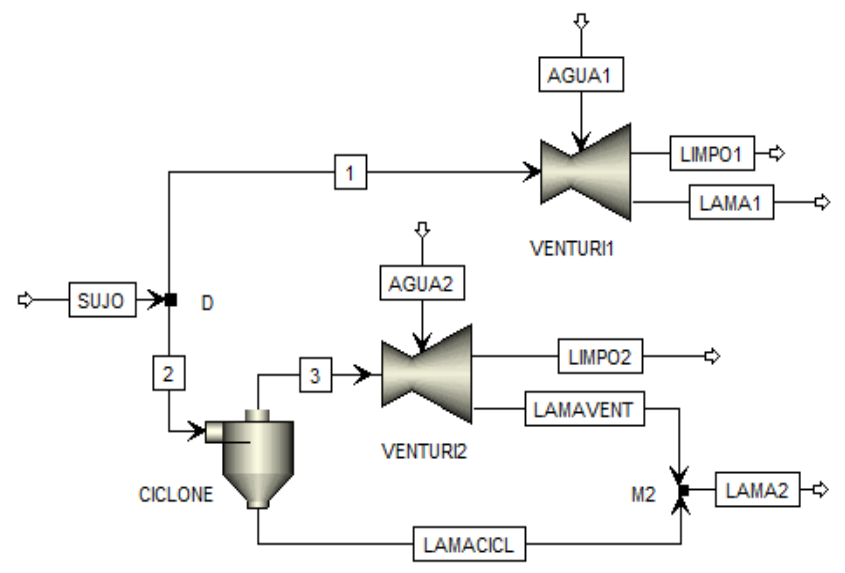

No fluxograma da Figura 2, o gás de saída da caldeira de queima de bagaço constituía a corrente SUJO. A partir de um recurso existente no simulador (bloco D), a corrente foi duplicada de forma que cada sistema de lavagem fosse alimentado com correntes iguais e os cálculos fossem executados simultaneamente pelo simulador. A corrente 1 alimentava o sistema composto apenas por um lavador Venturi (VENTURI1), cujo líquido de lavagem era fornecido pela corrente AGUA1; a corrente 2, por sua vez, alimentava o sistema composto por um ciclone (CICLONE) e um lavador Venturi (VENTURI2), cuja alimentação consistia na corrente de saída de gás de CICLONE (corrente 3). Para os lavadores VENTURI1 e VENTURI2, a corrente de gás de saída correspondia às correntes LIMPO1 e LIMPO2 respectivamente, ao passo que as correntes de lama formadas correspondiam respectivamente às correntes LAMA1 e 
LAMAVENT. A corrente de saída de particulado de CICLONE (corrente LAMACICL) era misturada (pelo bloco M2) à LAMAVENT1, originando a corrente LAMA2.

As características do gás de entrada foram extraídas do trabalho de Teixeira (2005). Era composto por $\mathrm{CO}_{2}(13,7 \%), \mathrm{O}_{2}(5,3 \%)$ e $\mathrm{N}_{2}(81 \%)$, com concentração de particulado igual a $3246,4 \mathrm{mg} / \mathrm{Nm}^{3}$ e temperatura de $436,45 \mathrm{~K}$. Nas simulações, utilizou-se a granulometria da Medição 1 exibida na Figura 1 (a) e considerou-se exclusivamente a presença de partículas de carbono sólido. Também estipulou-se que o líquido de lavagem era água a $298 \mathrm{~K}$ e que ambos os fluidos eram alimentados sob pressão de $101325 \mathrm{~Pa}$. Foi fixada uma vazão de gás na entrada de ambos os sistemas igual a $2,0 \mathrm{~m}^{3} / \mathrm{min}$.

Para o cálculo da eficiência e queda de pressão do lavador Venturi de ambos os sistemas, utilizou-se as equações de Yung et al. (1977). As dimensões do lavador correspondiam a um equipamento de bancada, com altura, comprimento e largura da garganta respectivamente iguais a 0,$04 ; 0,12$; e $0,027 \mathrm{~m}$.

Para o cálculo da eficiência do ciclone, utilizou-se o modelo de Leith e Licht (1972). Em relação à queda de pressão, foi utilizada a equação de Shepherd e Lapple (1939). As dimensões do ciclone (do tipo Stairmand de alta eficiência) correspondiam a um equipamento de bancada, com diâmetro da seção cilíndrica igual a $0,21 \mathrm{~m}$.

Neste trabalho, objetivou-se dar enfoque à influência da vazão de líquido injetado no equipamento de lavagem sobre a eficiência de coleta de material particulado, avaliando-se o consumo de água em ambos os processos. Assim, foram fixadas as variáveis referentes aos equipamentos, ou seja, não foram avaliadas as condições geométricas dos equipamentos durante as simulações.

Inicialmente, foi avaliada a influência da vazão de líquido injetado no lavador para dois sistemas de coleta de particulado: um lavador Venturi operando isoladamente (denominado VENTURI) e um sistema em série composto por um ciclone seguido por um lavador Venturi (denominado VENTURI+CICLONE). Foram simuladas operações de limpeza para 5 diferentes vazões de líquido injetado, iguais a 1,0;2,5;5,0;7,5; e 10,0 L/min. Para a avaliação dos sistemas de lavagem, foi considerada a concentração de particulado presente no gás de saída: o sistema de lavagem ideal deveria purificar o gás para que a concentração de particulado estivesse de acordo com os padrões de emissão do órgão responsável. Neste estudo, utilizou-se como referência os padrões de emissão para processos de combustão externa em fontes fixas de poluição com potências nominais totais até $70 \mathrm{MW}$ e superiores, igual a $120 \mathrm{mg} / \mathrm{Nm}^{3}$. Isto está de acordo com o porte da indústria cujos dados do gás de saída da queima de bagaço foram coletados (CONAMA, 1990; TEIXEIRA, 2005). Também foi avaliada a queda de pressão dos sistemas contabilizando-se exclusivamente a queda de pressão de seus equipamentos constituintes.

\section{RESULTADOS E DISCUSSÃO}

A Figura 3 apresenta os dados de concentração de saída de fuligem no gás de saída em função da vazão de líquido de lavagem, para ambos os sistemas avaliados. 


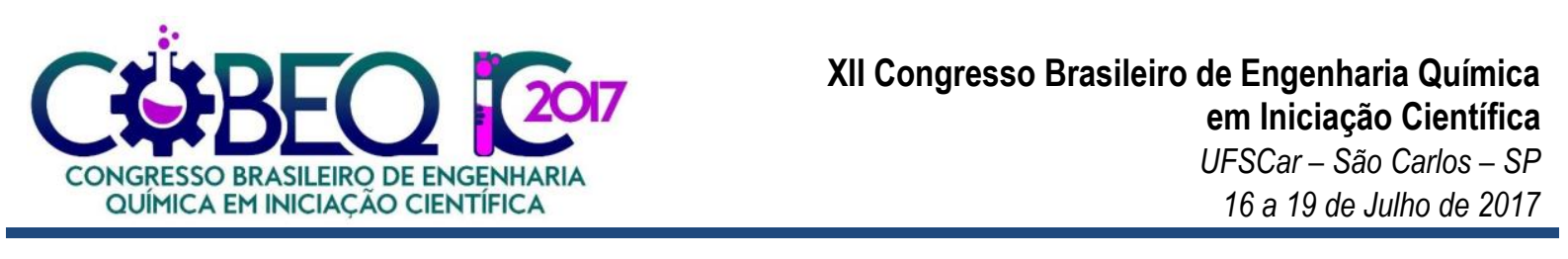

Figura 3 - Concentração de particulado na saída dos sistemas.

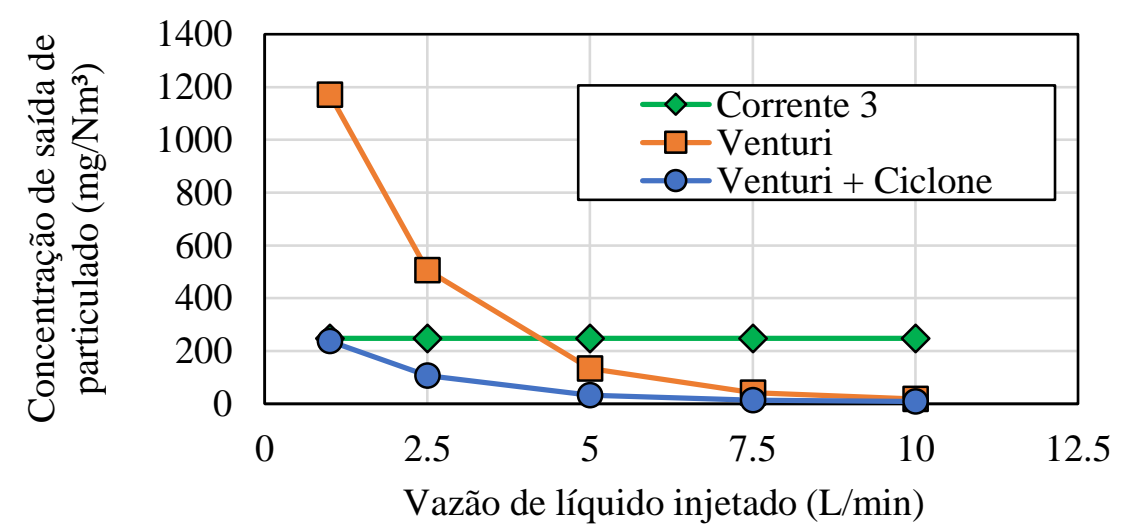

Na Figura 3, nota-se que a presença do ciclone resultou em um gás de saída mais limpo para cada vazão de líquido avaliada, a uma vazão fixa de gás. Esta diferença foi mais acentuada para baixas vazões de líquido, reduzindo-se à medida que esta variável aumentou. A concentração da corrente 3 (corrente de saída do ciclone) foi plotada juntamente às demais para efeitos comparativos: na saída do ciclone, a concentração foi aproximadamente igual a 245 $\mathrm{mg} / \mathrm{Nm}^{3}$. Observa-se que, para a menor vazão avaliada $(1,0 \mathrm{~L} / \mathrm{min})$, a concentração de saída do sistema VENTURI+CICLONE foi igual à da corrente 3, indicando que o lavador Venturi não foi eficaz para o tratamento do gás após a passagem no ciclone para esta vazão de líquido. De fato, para o sistema operando com o lavador isoladamente, a concentração de saída de particulado foi singularmente alta. $\mathrm{O}$ aumento da vazão de líquido no lavador, fixadas as condições de alimentação do gás, resultou em aumento da razão líquido-gás. Desta forma, maior se tornou a quantidade de gotículas de líquido disponíveis para a captura do particulado presente no meio gasoso, proporcionando aumento da eficiência do processo e na obtenção de um gás de saída com menor concentração de partículas sólidas.

O separador ciclônico disposto anteriormente ao lavador capturou partículas maiores e as retirou do gás em tratamento: enquanto separadores inerciais, os ciclones capturam material particulado a partir da inércia das partículas sólidas e sua diferença de densidade em relação à densidade do fluido carreador. Assim, o particulado não adquire aceleração centrípeta tal como as moléculas do fluido e, ao cruzar suas linhas de corrente, colide com as paredes do equipamento. Desta forma, a concentração de sólidos na entrada do lavador foi menor que a de alimentação do sistema VENTURI. Pode-se inferir, deste modo, que a quantidade de gotículas de líquido disponíveis para a captura de uma única partícula era maior para o sistema VENTURI+CICLONE, avaliando-se a uma mesma vazão de líquido para a vazão fixa de gás. Verifica-se que, para atender ao padrão de emissão estabelecido pelo CONAMA, igual a 120 $\mathrm{mg} / \mathrm{Nm}^{3}$, o sistema VENTURI utilizou aproximadamente 5,4 L/min de líquido de lavagem nas condições fixadas da corrente gasosa, ao passo que o sistema VENTURI+CICLONE necessitou de aproximadamente $2,4 \mathrm{~L} / \mathrm{min}$, o que representou $44,44 \%$ da vazão necessária em relação ao uso de um lavador operando isoladamente sob as mesmas condições geométricas e de operação.

A Figura 4 apresenta os dados de queda de pressão em função da vazão de líquido de lavagem, para ambos os sistemas avaliados. 


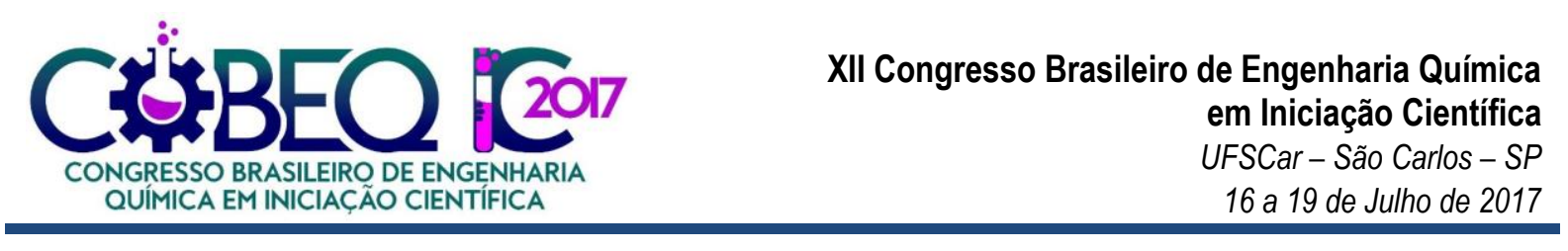

Figura 4 - Queda de pressão total dos sistemas.

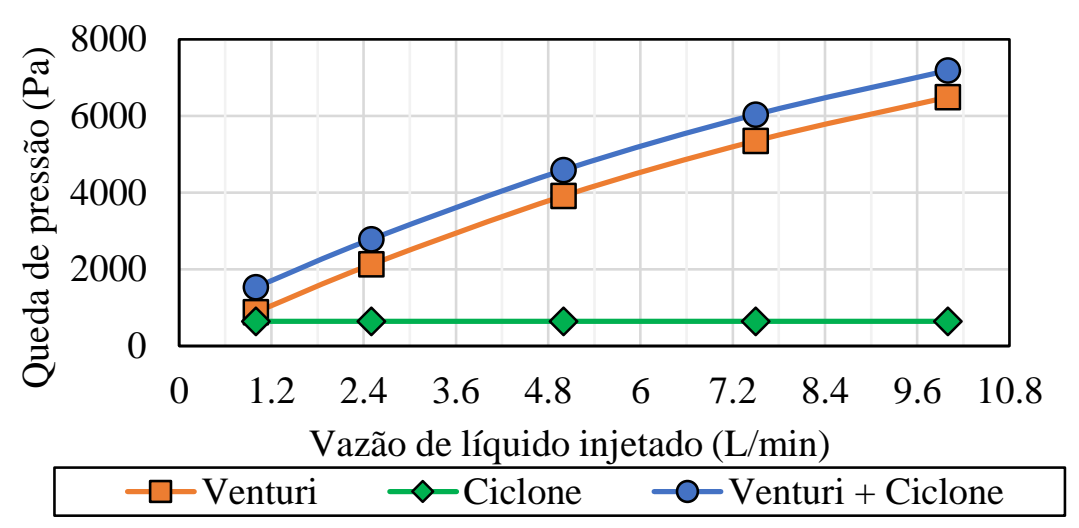

A análise da queda de pressão (Figura 4) foi restrita para os sistemas operando de forma que a concentração de particulado de saída correspondesse a $120 \mathrm{mg} / \mathrm{Nm}^{3}$. Dessa forma, para o sistema VENTURI, a queda de pressão correspondente à vazão de líquido de 5,4 L/min foi aproximadamente igual a $5000 \mathrm{~Pa}$, enquanto que, para o sistema VENTURI+CICLONE à vazão de líquido de 2,4 L/min, foi aproximadamente igual a $3000 \mathrm{~Pa}$, equivalente a $60 \%$ do atingido pelo outro sistema. Isto quer dizer que, nas mesmas condições geométricas do lavador e de alimentação dos sistemas para a obtenção de uma concentração de emissão de particulado que obedecesse à norma vigente, o sistema VENTURI+CICLONE não apenas necessitou de menor consumo de água, como também de menor consumo de energia (avaliando-se exclusivamente a queda de pressão dos equipamentos de cada sistema).

A principal fonte de queda de pressão da lavagem é a energia mecânica do gás necessária para atomizar as gotas de líquido: ao atravessar a garganta do lavador a uma mesma vazão volumétrica, a energia cinética do gás aumenta. Esta energia é parcialmente transferida às gotas do líquido, que são atomizadas. Deste modo, a superfície de contato total entre gás e líquido aumenta e a probabilidade de as gotículas capturarem o material particulado presente na corrente gasosa cresce. Entretanto, a transferência de energia para o líquido ocasiona queda de pressão no gás. Disto, infere-se que a redução do consumo de água de lavagem para uma mesma vazão de ar proporcionou redução da transferência de energia necessária para atomizar as gotas de líquido e, consequentemente, reduziu a queda de pressão.

Também foi plotada a queda de pressão do ciclone na Figura 4 para efeitos comparativos. É possível verificar a baixa queda de pressão relativa à operação no ciclone, de aproximadamente $644 \mathrm{~Pa}$ para as condições especificadas. Perdas de energia do gás devido à fricção nas paredes do equipamento e na tubulação, parcialmente compensadas pela recuperação de energia na saída do ciclone, são responsáveis pela queda de pressão no separador ciclônico. Entretanto, tal perda de energia é baixa quando comparada à queda de pressão no lavador. Assim, em termos de queda de pressão global, o sistema VENTURI+CICLONE demandou menor energia que o sistema VENTURI para cumprir o mesmo objetivo.

\section{CONCLUSÕES}

Nas condições geométricas e de operação utilizadas, o sistema composto por um ciclone em série com um lavador Venturi consumiu 44,44\% de água e obteve $60,0 \%$ da queda de 
pressão de um sistema com lavador Venturi atuando isoladamente para atender ao mesmo requisito de emissão de particulado.

O aumento da vazão do líquido de lavagem reduziu a concentração de particulado no gás de saída. Entretanto, foi o maior responsável pelo aumento da queda de pressão.

\section{NOMENCLATURA}

ICIDCA - Instituto Cubano de Pesquisa dos Derivados da Cana-de-açúcar CONAMA - Conselho Nacional do Meio Ambiente EPA - Environmental Protection Agency $\mathrm{PM}_{10}$ - Material particulado (Particulate Matter) de diâmetro menor que $10 \mu \mathrm{m}$ WHO - World Health Organization (Organização Mundial de Saúde)

\section{REFERÊNCIAS BIBLIOGRÁFICAS}

CONSELHO NACIONAL DO MEIO AMBIENTE (CONAMA). Dispõe sobre o estabelecimento de limites máximos de emissão de poluentes no ar para processos de combustão externa de fontes fixas de poluição. Resolução CONAMA n ${ }^{\circ} 8$, de 6 de dezembro de 1990. DOU, 28 dez. 1990, p. 25539.

INSTITUTO CUBANO DE PESQUISA DOS DERIVADOS DA CANA-DE-AÇÚCAR. Manual dos derivados da cana-de-açúcar: diversificação, matérias-primas, derivados do bagaço, derivados do melaço, outros derivados, resíduos, energia. Brasília: ABIPTI, 1999.

LEITH; LICHT, 1972 apud DIRGO, J.; LEITH, D. Cyclone collection efficiency: comparison of experimental results with theoretical predictions. Aerosol Science and Technology, 4. p. $401-415,1985$. p. 405.

SHEPHERD; LAPPLE, 1939 apud CHUAH, T. G.; GIMBUN, J.; CHOONG, T. S. Y.; FAKHRU'L-RAZI, A. Numerical prediction of cyclone pressure drop. Journal of Chemical Engineering and Environment, vol. 2, n. 2, p. 67 - 71, 2003. p. 68.

SUTHERLAND, K. Filters and Filtration Handbook. 5th ed. Elsevier, 2008.

TEIXEIRA, F. N. Caracterização e controle das emissões de óxidos de nitrogênio e material particulado em caldeiras para bagaço. Tese de Doutorado. Instituto de Engenharia Mecânica, Universidade Federal de Itajubá, Itajubá, 2005. 274 f.

WORLD HEALTH ORGANIZATION (WHO). WHO Air quality guidelines for particulate matter, ozone, nitrogen dioxide and sulfur dioxide. Global update 2005 - Summary of risk assessment. $2006 . \quad$ Disponível em: <http://www.who.int/phe/health_topics/outdoorair/outdoorair_aqg/en/>. Acesso em: 1 dez. 2016.

YUNG, S.; CALVERT, S.; BARBARIKA, H. F. Venturi scrubber performance model. Washington: U. S. Environmental Protection Agency, 1977. 